\title{
Pengaruh Range of Motion (ROM) Aktif Kaki terhadap Risiko terjadinya Ulkus Kaki Diabetik pada Pasien Diabetes Mellitus Tipe 2 di Desa Kaliwining Kabupaten Jember (The Effect of Active Leg Range of Motion on the Risk of Diabetik Foot Ulcer in Patient with Type 2 Diabetes Mellitus at Kaliwining Village of Jember Regency)
}

\author{
Yulfa Intan Lukita, Nur Widayati, Wantiyah \\ Fakultas Keperawatan Universitas Jember \\ JI. Kalimantan No. 37 Kampus Tegal Boto Jember Telp./Fax. (0331) 323450 \\ e-mail: wantiyah.psik@unej.ac.id
}

\begin{abstract}
Diabetic foot ulcer is one of serious complications in diabetic patients which can lead to amputation. Active Leg range of motion (ROM) exercise is one of physical activities which can improve blood circulation in lower extremities. The objective of this research was to analyze the effect of active leg ROM on the risk of diabetic foot ulcer. This research employed non randomized control group pretest postest design. The sampling technique was purposive sampling involving 30 repondents which were divided into 15 respondents as intervention group and 15 respondents as control group. The data were analyzed using dependent $t$ test and independent $t$ test with significant level of 0.05 . The result revealed a significant difference between pretest and posttest in the intervention group ( $p=$ $0.000)$ but no significant difference in the control group $(p=0.582)$. Furthemore, independent $t$ test showed a significant difference between intervention group and control group $(p=0.000)$. This result indicates that there is a significant effect of active leg ROM on the risk of diabetic foot ulcer in client with type 2 diabetes mellitus. Nurse is expected to apply range of motion as one of intervention to prevent diabetic foot ulcer in diabetes mellitus patients.
\end{abstract}

Keywords: type 2 diabetes mellitus, active leg range of motion, risk of diabetic foot ulcer

\begin{abstract}
Abstrak
Salah satu komplikasi yang disebabkan oleh diabetes melitus adalah ulkus kaki diabetik. Salah satu penanganan diabetes melitus untuk mengurangi risiko ulkus kaki diabetik adalah latihan Range of Motion (ROM) aktif kaki yang dapat melancarkan sirkulasi darah ekstremitas bawah. Tujuan penelitian ini adalah menganalisa pengaruh ROM aktif kaki terhadap risiko ulkus kaki diabetik. Teknik pengambilan sampel menggunakan purposive sampling dengan jumlah sampel 30 orang yang dibagi menjadi 15 orang pada kelompok perlakuan dan 15 orang pada kelompok kontrol. Data penelitian ini dianalisis menggunakan uji t dependen dan uji $t$ independen dengan tingkat signifikan 0,05 . Hasil uji t dependen menunjukkan adanya perbedaan signifikan nilai risiko ulkus kaki diabetik sebelum dan sesudah dilakukan ROM aktif kaki pada kelompok perlakuan $(p=0,000)$. Pada kelompok kontrol juga ditemukan penurunan risiko ulkus kaki diabetik antara pretest dan posttest namun tidak signifikan $(p=0,582)$. Hasil uji $t$ independent menunjukkan perbedaan signifikan antara kelompok perlakuan dan kelompok kontrol $(p=0,000)$. Kesimpulan penelitian ini adalah terdapat pengaruh ROM aktif kaki terhadap risiko ulkus kaki diabetik pada pasien DM tipe 2. Perawat diharapkan dapat menerapkan latihan ROM aktif kaki sebagai salah satu intervensi untuk mencegah timbulnya ulkus kaki diabetik.
\end{abstract}

Kata kunci: diabetes melitus tipe 2, ROM aktif kaki, risiko ulkus kaki diabetik 


\section{Pendahuluan}

Diabetes merupakan kumpulan penyakit metabolik yang ditandai dengan hiperglikemia akibat kelainan sekresi insulin, kerja insulin, atau keduanya [1]. Pasien DM tidak dapat menyerap glukosa dengan benar sehingga glukosa tetap beredar dalam darah, kondisi seperti ini disebut dengan hiperglikemia [2]. Masalah tersering yang dialami pasien DM adalah komplikasi berupa neuropati perifer yang berkembang menjadi ulkus kaki hingga menyebabkan amputasi ekstremitas bawah. Pasien DM mempunyai risiko lebih besar mengalami ulkus kaki diabetik sehingga pasien DM membutuhkan penanganan serius [3].

Prevalensi DM pada orang dewasa usia 20 - 79 tahun di seluruh dunia pada tahun 2015 meningkat menjadi 415 juta dan diperkirakan akan mencapai 642 juta pada tahun 2040. Jumlah pasien DM di Indonesia meningkat dari 9,116 juta orang pada tahun 2014 menjadi 10 juta orang pada tahun 2015 [4]. Prevalensi DM di Jawa Timur mengalami peningkatan dari tahun 2007 yaitu sebesar 1,8\% menjadi 2,5\% pada tahun 2013 [5]. Data Dinas Kesehatan Kabupaten Jember pada tahun 2015 menunjukkan jumlah kunjungan pasien DM tipe 2 adalah 7.513 kunjungan [6]. Kunjungan pasien DM tipe 2 terbanyak kedua adalah Puskesmas Rambipuji dengan 911 kunjungan dari bulan Januari 2015 hingga Januari 2016 dan jumlah pasien DM pada bulan Mei 2015 hingga Januari 2016 adalah 203 orang. Desa yang memiliki jumlah pasien terbanyak di Kecamatan Rambipuji adalah Desa Kaliwining dengan jumlah pasien 67 orang. Hasil studi pendahuluan kepada 10 orang pasien DM tipe 2 di Desa Kaliwining menyatakan sering mengalami gejala neuropati diabetik seperti kedua kakinya terasa tebal, kesemutan, panas seperti terbakar, nyeri seperti tertusuk jarum, dan terkadang mati rasa. Salah satu dari sepuluh orang tersebut memiliki riwayat ulkus kaki diabetik.

Ulkus kaki diabetik terjadi akibat neuropati perifer, insufisiensi pembuluh perifer, dan infeksi. Gangguan tersebut terjadi akibat penimbunan sorbitol dalam intima vaskular, hiperlipoproteinemia, dan kelainan pembekuan darah. Hal tersebut dapat menyebabkan Terhambatnya sirkulasi darah di kaki dan mengakibatkan rasa sakit pada betis kaki saat berjalan, luka diabetes, gangguan sistem saraf, dan rentan terhadap infeksi di kaki [7]. Gejala neuropti diabetik pada pasien DM menunjukkan adanya penurunan aliran darah dan hantaran oksigen pada serabut saraf sehingga mengakibatkan degenerasi pada serabut saraf [8]. Keadaan ini mengakibatkan sensasi terhadap rangsang sakit menurun dan terjadi perubahan kekuatan motorik sehingga timbul perubahan pada telapak kaki [9]. Pasien DM yang disertai neuropati meningkatkan risiko terjadinya ulkus kaki diabetik tujuh kali lebih besar [10].

Salah satu cara untuk mencegah terjadinya risiko ulkus kaki diabetik adalah dengan melakukan latihan jasmani [3]. Range of Motion (ROM) aktif kaki adalah salah satu bentuk latihan jasmani yang dapat dilakukan oleh pasien DM. Latihan ROM merupakan salah satu intervensi keperawatan yang dapat dilakukan oleh pasien maupun keluarga secara mandiri setelah memperoleh pendidikan kesehatan sebelumnya [11]. Saat melakukan latihan ROM aktif kaki, otot-otot kaki berkontraksi secara terus menerus dan terjadi kompresi pembuluh darah sehingga dapat mengaktifkan pompa vena [12]. Pembuluh darah balik akan lebih aktif memompa darah ke jantung sehingga sirkulasi darah arteri yang membawa nutrisi dan oksigen ke pembuluh darah perifer menjadi lebih lancar [13]. Aliran darah yang lancar akan memudahkan nutrien masuk ke dalam sel sehingga dapat memperbaiki fungsi saraf dan mencegah timbulnya neuropati, dengan begitu latihan fisik merupakan faktor dominan dalam pencegahan ulkus kaki diabetik [14]. Berdasarkan permasalahan di atas maka peneliti ingin menganalisis pengaruh ROM aktif kaki terhadap risiko terjadinya ulkus kaki diabetik.

\section{Metode Penelitian}

Metode penelitian menggunakan quasi experimental dengan desain penelitian non randomized control group pretest postest. Populasi penelitian ini adalah pasien DM tipe 2 di Desa Kaliwining sebanyak 67 pasien. Kriteria inklusi penelitian ini adalah usia 45-65 tahun, mengalami $\mathrm{DM} \geq 5$ tahun, pasien mampu berdiri, mampu melaksanakan aktivitas mandiri, pemeriksaan KGD tidak lebih dari $300 \mathrm{mg} / \mathrm{dL}$ dan tidak kurang dari $70 \mathrm{mg} / \mathrm{dL}$, serta bersedia menjadi responden penelitian. Kriteria eksklusi responden adalah pasien yang memiliki ulkus kaki diabetik, memiliki penyakit penyerta yang dapat mengganggu penelitian (gagal ginjal kronik, gagal jantung, gangguan pengelihatan, tuli, dan lain sebagainya), pasien memiliki tandatanda hipoglikemia, pasien mengalami 
gangguan persendian, pasien mengalami sesak nafas, pasien dengan paska trauma, dan pasien tidak mengikuti keseluruhan kegiatan atau mengundurkan diri. Teknik pengambilan sampel dalam penelitian ini menggunakan purposive sampling. Jumlah sampel yang diambil adalah 30 responden, 15 pasien pertama dijadikan sebagai kelompok responden dan 15 pasien berikutnya dijadikan sebagai kelompok kontrol.

Penelitian ini dilaksanakan di Desa Kaliwining Kecamatan Rambipuji Kabupaten Jember. Waktu pengumpulan data dilakukan pada bulan April 2016. Latihan dilakukan 27x dalam 2 minggu, yaitu $2 x$ perhari pada 13 hari pertama dan $1 x$ per hari pada hari ke-14. Posttest dilakukan setelah latihan terakhir. Teknik pengumpulan data dalam penelitian ini menggunakan nilai risiko ulkus kaki diabetik yang diukur dengan lembar observasi inlow's 60 -second diabetic foot screen screening tool. Data dianalisis dengan menggunakan uji $t$ dependen dan uji $t$ independen dengan derajat kepercayaan $95 \%\left({ }_{0}=0,05\right)$.

\section{Hasil Penelitian}

Nilai Risiko Ulkus Kaki Diabetik pada Kelompok Perlakuan dan Kelompok Kontrol

Tabel 1. Nilai Risiko Ulkus Kaki Diabetik Pretest dan Posttest pada Kelompok Perlakuan dan Kontrol

\begin{tabular}{ccc}
\hline $\begin{array}{c}\text { Variabel nilai } \\
\text { risiko ulkus kaki } \\
\text { diabetik }\end{array}$ & Mean & $\begin{array}{c}\text { Mean } \\
\text { difference }\end{array}$ \\
& &
\end{tabular}

\begin{tabular}{|c|c|c|c|}
\hline & Pretest & $\begin{array}{c}\text { Postte } \\
\text { st }\end{array}$ & \\
\hline $\begin{array}{l}\text { Kelompok } \\
\text { pelakuan }\end{array}$ & 7,40 & 5,13 & 2,267 \\
\hline Kelompok kontrol & 7,73 & 7,60 & 0,133 \\
\hline
\end{tabular}

Tabel 1 menunjukkan bahwa terjadi penurunan rata-rata nilai risiko ulkus kaki diabetik pada kelompok perlakuan sebesar 2,267 yaitu dari 7,40 menjadi 5,13. Pada kelompok kontrol terjadi penurunan rata-rata nilai $A B I$ sebesar 0,133 yaitu dari 7,73 menjadi 7,60. Niai mean difference positif menunjukkan adanya penurunan nilai rata-rata risiko ulkus kaki diabetik.

Tabel 2 menunjukkan jumlah responden dengan risiko ulkus kaki diabetik kategori sedang berkurang dari 10 responden $(66,7 \%)$ menjadi 1 responden $(6,7 \%)$ pada kelompok perlakuan. Pada kelompok kontrol, Jumlah responden dengan risiko ulkus kaki kategori sedang berkurang dari 10 responden $(66,7 \%)$ menjadi 9 responden (60\%).
Tabel 3. Hasil Uji t Dependen Nilai Risiko Ulkus Kaki Diabetik pada Kelompok Perlakuan dan Kelompok Kontrol

\begin{tabular}{|c|c|c|c|c|}
\hline Kelompok & $\begin{array}{c}\text { Nilai } \\
\text { Risiko } \\
\text { Ulkus } \\
\text { Kaki } \\
\text { Diabetik }\end{array}$ & Mean & $\begin{array}{c}\text { Mean } \\
\text { Differenc } \\
e\end{array}$ & $p$ \\
\hline Perlakuan & $\frac{\text { Pretest }}{\text { Posttest }}$ & $\frac{7,40}{5,13}$ & 2,267 & 0,000 \\
\hline Kontrol & $\begin{array}{l}\text { Petest } \\
\text { Posttest }\end{array}$ & $\begin{array}{l}7,73 \\
7,60\end{array}$ & 0,133 & 0,582 \\
\hline
\end{tabular}

Tabel 3 menunjukan kelompok perlakuan memiliki nilai $p=0,000(p<0,05)$, artinya terdapat penurunan nilai risiko ulkus kaki diabetik yang signifikan sebelum dan sesudah dilakukan ROM aktif kaki. Hasil uji $t$ dependen pada kelompok kontrol diketahui nilai $p=0,582$ ( $p>0,05)$, artinya terjadi penurunan nilai ulkus kaki diabetik yang tidak signifikan antara pretest dan posttest pada kelompok kontrol.

Tabel 4. Hasil Uji t Independen Nilai Risiko Ulkus Kaki Diabetik antara Kelompok Perlakuan dan Kelompok Kontrol

\begin{tabular}{lll}
\hline \multicolumn{1}{c}{ Variabel } & $\begin{array}{c}\text { Mean } \\
\text { Difference }\end{array}$ & $p$ \\
\hline $\begin{array}{l}\text { Risiko ulkus kaki diabetik } \\
\text { kelompok perlakuan }\end{array}$ & 2,267 & 0,000 \\
\cline { 1 - 1 } $\begin{array}{l}\text { Risiko ulkus kaki diabetik } \\
\text { kelompok kontrol }\end{array}$ & 0,133 & \\
\hline
\end{tabular}

Tabel 4 menunjukkan hasiluji $t$ independent pada variabel risiko ulkus kaki diabetik kelompok perlakuan dan kelompok kontrol, yaitu nilai p 0,000 yang berarti $p<a$ $(0,05)$. Hasil tersebut menunjukkan terjadi penurunan risiko ulkus kaki diabetik yang lebih besar pada kelompok perlakuan dibanding kelompok kontrol sehingga dapat disimpulkan adanya pengaruh ROM aktif kaki terhadap risiko ulkus kaki diabetik

\section{Pembahasan \\ Nilai Risiko Ulkus Kaki Diabetik Sebelum dan Sesudah ROM Aktif Kaki pada Kelompok Perlakuan}

Hasil penelitian ini menunjukan setelah dilakukan latihan ROM aktif kaki pada kelompok perlakuan terjadi penurunan yang signifikan rata-rata nilai risiko ulkus kaki diabetik sebesar 2,267 . Penurunan ini bisa disebabkan oleh latihan ROM aktif kaki yang dilaksanakan 2 kali sehari pada 13 hari pertama dan 1 kali sehari pada hari ke 14 .

Penimbunan sorbitol dalam intima vaskuler dan hiperlipoproteinemia yang disebabkan oleh hiperglikemi mengakibatkan penyumbatan 
vaskuler. Jika hal ini terjadi pada arteri perifer dapat mengakibatkan insufisiensi pembuluh darah perifer yang disertai klaudikasio intermiten [21]. Gangguan sirkulasi darah pada ekstremitas bawah dapat mengakibatkan penurunan hantaran oksigen pada jaringan dan menyebabkan degenerasi serabut saraf [8]. Keadaan ini mengakibatkan sensasi terhadap rangsang sakit menurun dan terjadi perubahan kekuatan motorik sehingga timbul perubahan tekanan pada telapak kaki serta produksi keringat yang berkurang (neuropati autonomik) yang mengakibatkan kulit menjadi kering. Saat terjadi trauma kecil, keadaan kaki yang mudah retak meningkatkan risiko terjadinya ulkus kaki diabetik [9].

Gerakan yang dilakukan saat latihan ROM aktif kaki mampu membuat otot kaki berkontraksi terus menerus sehingga terjadi kompresi pembuluh darah di dalamnya dan mengaktifkan pompa vena. Aliran darah akan sangat meningkat diantara fase kontraksi dan relaksasi. Saat kontraksi aliran darah akan mengalir menuju vena dan akan terisi kembali dari arteri saat fase relaksasi [12,13]. Pembuluh darah balik akan lebih aktif memompa darah ke jantung sehingga sirkulasi darah arteri yang membawa nutrisi dan oksigen ke pembuluh darah perifer menjadi lebih lancar [13].

Peningkatan aliran darah mempermudah saraf menerima suplai oksigen dan nutrisi sehingga dapat meningkatkan fungsi saraf [22]. Fungsi saraf yang baik dapat mengurangi neuropati diabetik yang memiliki gejala bermacam-macam sesuai saraf yang terganggu seperti kesemutan, rasa tebal, dan nyeri [23].

\section{Nilai Risiko Ulkus Kaki Diabetik Pretest dan Posttest pada Kelompok Kontrol}

Hasil penelitian menunjukkan terjadi penurunan risiko ulkus kaki diabetik pada kelompok kontrol sebesar 0,133 dari rata-rata pretest 7,73 menjadi 7,60 pada saat posttest. Pasien DM pada kelompok kontrol tidak diberikan latihan fisik berupa ROM aktif kaki dan melakukan aktivitas sesuai dengan kebiasaan sehari-hari. Pasien DM pada kelompok kontrol mengalami penurunan risiko ulkus kaki diabetik bisa dimungkinkan karena beberapa responden menerapkan pola hidup sehat seperti melakukan aktivitas fisik.

Aktivitas fisik sehari-hari yang dilakukan secara teratur seperti menggunakan tangga, dan berkebun dapat menjaga kebugaran jasmani dan menurunkan berat badan serta memperbaiki sensitivitas insulin sehingga membantu dalam kendali kadar gula darah [3]. Sebagian besar pasien pada penelitian ini diketahui memiliki aktivitas fisik di luar rumah seperti bekerja.

Faktor lain yang kemungkinan mampu menurunkan risiko ulkus kaki diabetik pada kelompok kontrol adalah konsumsi OHO. Pasien yang patuh mengkonsumsi obat hipogliemi memiliki kadar gula darah yang terkontrol [20]. Pada penelitian ini, mayoritas pasien kelompok kontrol mengkonsumsi OHO. Hasil penelitian ini menunjukkan rata-rata kadar gula darah pasien kelompok kontrol pada saat pretest yaitu 223,39 $\mathrm{mg} / \mathrm{dL}$ dan pada saat posttest yaitu 215,47 $\mathrm{mg} / \mathrm{dL}$. Terjadi penurunan rata-rata nilai KGD pada kelompok kontrol yang kemungkinan menjadi salah satu faktor turunnya nilai ulkus kaki diabetik pada kelompok kontrol.

Kebiasaan tidak merokok pada kelompok kontrol dimungkinkan menjadi kondisi yang mendukung untuk terjadinya penurunan risiko ulkus kaki diabetik pada kelompok kontrol. Rokok menyebabkan kerusakan endotel yang kemudian menyebabkan agregasi trombosit sehingga mempermudah terjadinya arterosklerosis. Kejadian ini mengakibatkan sirkulasi darah tidak lancar dan suplai oksigen ke jaringan berkurang. Keadaan ini mengakibatkan sensasi terhadap rangsang sakit menurun, perubahan kekuatan motorik, perubahan tekanan pada telapak kaki serta produksi keringat yang berkurang (neuropati autonomik), keadaan kaki meningkatkan risiko terjadinya ulkus kaki diabetik [8,9].

\section{Pengaruh Pemberian ROM Aktif Kaki tehadap Risiko Ulkus Kaki Diabetik}

Uji $t$ independent menunjukkan nilai $p=$ 0,000 , yang berarti $p<\alpha(0,05)$, artinya ada perbedaan signifikan risiko ulkus kaki diabetik antara kelompok perlakuan dengan kelompok kontrol. Hal ini menunjukkan adanya pengaruh ROM aktif kaki terhadap risiko ulkus kaki diabetik.

Latihan ROM berfungsi untuk meningkatkan kekuatan otot dan reflek tendon, memperbaiki sensasi proteksi dan nilai $A B I$, serta meminimalisasi keluhan polineuropati diabetikum sehingga mampu mencegah komplikasi ulkus kaki diabetik [27]. Saat melakukan aktivitas fisik seperti ROM aktif kaki, otot berkontraksi secara terus menerus sehingga terjadi kompresi pembuluh-pembuluh darah di dalamnya dan mengaktifkan pompa vena. Aliran darah akan sangat meningkat diantara fase kontraksi dan relaksasi. Sirkulasi 
darah yang lancar dapat mencegah terjadinya risiko ulkus kaki diabetik. [12,13].

Aktivitas fisik membuat pembuluh darah terpapar dengan keadaan hiperemia secara berulang. Hal tersebut meningkatkan ekpresi nitrit oxide synthase (NOS) dan melepaskan NO. NO berfungsi untuk menjaga endotel (lapisan dinding). NO dapat merangsang pembentukan endothelial derive relaxing factor (EDRF) yang menjadi faktor penting dalam vasodilatasi atau pelebaran arteri. Konsentrasi NO dapat membantu mempertahankan suplai darah yang cukup sehingga melindungi pembuluh darah dari agregasi trombosit dan aterosklerosis [24].

Selain meningkatkan sirkulasi darah, ROM juga bermanfaat memelihara mobilitas persendian. Kontraksi otot yang terjadi saat melakukan latihan ROM dapat meningkatkan sirkulasi darah ke dalam kapsula sendi dan memberikan nutrisi yang dapat mempermudah pergerakan tulang tanpa adanya rasa nyeri [25]. Keterbatasan mobilitas sendi merupakan penyebab tekanan plantar kaki tidak normal sehingga mengakibatkan ulkus kaki diabetik pada penderita DM. Setiap keterbatasan mobilitas sendi dapat meningkatkan tekanan plantar kaki selama berjalan. Saat kaki tidak mampu bergerak bebas, tekanan pada plantar kaki tidak merata sehingga mengakibatkan kerusakan jaringan pada daerah yang memiliki tekanan plantar kaki tinggi. Keterbatasan gerak sendi dapat menyebabkan kelemahan otot hingga atrofi. Hal ini mengakibatkan perubahan gaya berjalan pada pasien DM sehingga pasien DM dapat mengalami deformitas [26,27].

Manfaat lain dari ROM aktif kaki adalah meningkatkan rerata nilai sensasi proteksi pada pasien DM tipe 2 [28]. Kegagalan sensasi proteksi yang diakibatkan oleh neuropati merupakan faktor umum terjadinya ulkus kaki diabetik. Neuropati diabetik disebabkan oleh peningkatan kadar gula darah yang kronis sehingga mengakibatan terjadinya demyelinasi multifokal dan hilangnya akson (axonal loss) sehingga pasien DM dengan neuropati akan kehilangan sensasi dalam merasakan nyeri, panas, vibrasi dan tekanan [28, 29]. Aktivitas fisik dapat membantu meningkatkan sirkulasi darah dan memperkuat otot-otot kecil kaki sehingga membantu menstimuli saraf-saraf kaki menerima rangsang [30].

Hasil peneltian ini, indikator risiko ulkus kaki diabetik yang paling banyak mengalami penurunan adalah keluhan neuropati seperti kebas, nyeri seperti terbakar, kesemutan dan perbaikan nilai sensitifitas kaki. Aktivitas fisik seperti ROM aktif kaki mampu melancarkan sirkulasi darah sehingga mampu memperbaiki kerusakan saraf sehingga dapat mengurangi gejala neuropati pada pasien DM [28].

\section{Simpulan dan Saran}

Terdapat pengaruh ROM aktif kaki terhadap risiko ulkus kaki diabetik pada pasien DM tipe 2. ROM aktif kaki dapat meningkatkan sirkulasi darah ekstemitas bawah sehingga menurunkan risiko ulkus kaki diabetik pada pasien DM tipe 2.

Perawat dapat memberikan pendidikan kesehatan mengenai ROM aktif kaki sehingga risiko ulkus kaki diabetik dapat diminimalkan. Bagi peneliti selanjutnya diperlukan durasi latihan yang lebih lama dan jumlah responden yang lebih banyak dengan pengontrolan faktorfaktor yang mempengaruhi ulkus kaki diabetik.

\section{Daftar pustaka}

[1] American Diabetes Association. Type 2 diabetes mellitus. [Internet] ADA; 2014 [diambil tanggal 25 November 2015]; dari: http://www.diabetes.org/diabetesbasics/statistics/

[2] International Diabetes Federation. IDF diabetes atlas : sixth edition. [Internet] IDF; 2013 [diambil tanggal 02 Juni 2015]; dari: http://www.idf.org/sites/default/files/EN_6E_ Atlas_Full_0.pdf

[3] Perkumpulan Endokrinologi Indonesia. Konsensus pengelolaan diabetes melitus di Indonesia. [Internet] PERKENI, 2011 [diambil tanggal 26 November 2011]; dari: https://www.scribd.com/doc/234334110/Kon sensus-DM-Perkeni-2011\#download

[4] International Diabetes Federation. IDF diabetes atlas : 7th edition. [Internet] IDF;2015 [diambil tanggal 12 Januai 2016]; dari: $\quad$ http://www.diabetesatlas.org/keymessages.html

[5] Badan Penelitian dan Pengembangan Kesehatan Depkes RI. Riset Kesehatan Dasar (RISKESDAS) 2013. Jakarta : Badan Penelitian dan Pengembangan Kesehatan Depkes Rl; 2013

[6] Dinas Kesehatan Kabupaten Jember. Laporan kunjungan DM Kabupaten Jember tahun 2015. Jember : Dinas Kesehatan Kabupaten Jember; 2015

[7] Mahendra. Care your self : diabetes mellitus [Intenet] Jakarta : 2008.[diambil tanggal 1 Juni 2015]; dari: https://books.google.co.id/books? id=iu18116ceAEC\&pg=PA17\&dq=Dampak+ 
$\underline{\text { diabetes }+ \text { mellitus\&hl=en\&sa }=X \& e i=h Y F r V Z}$ CUHdWcugTD-

[8] Hastuti R. Faktor risiko ulkus diabetika pada penderita diabetes melitus. Tesis. Semarang: Program Studi Magister Epidemiologi Universitas Diponegoro; 2008.

[9] Lumenta NA. Manajemen hidup sehat [Internet] Jakarta: PT Elex Media Komputindo; 2006. [diambil tanggal 16 Oktober 2015] dari: https://books.google.co.id/books? id=g5Lbitu6jPoC\&pg=PA30\&dq=perjalanan +kaki+diabetik\&hl=en\&sa

[10] Roza RL, Afriant R, Edward Z. Faktor risiko terjadinya ulkus diabetikum pada pasien diabetes melitus yang dirawat jalan dan inap di RSUP Dr. M.Djamil dan RSI Ibnu Sina Padang. Jurnal Kesehatan Andalas [Internet]. 2015 [diambil tanggal 17 Januari 2016];4(1):243-247. dari: http://jurnal.fk.unand.ac.id/index.php/jka/arti cle/view/229

[11] Taufiq I. Pengaruh latihan Range of Motion (ROM) ankle terhadap proses penyembuhan ulkus kaki diabetik di RSUD Dr.Hi.Abdul Moeloek dan RSUD Jendral A.Yani Propinsi Lampung. Tesis. Depok: Program Studi Pascasarjana Ilmu Keperawatan Universitas Indonesia;2011

[12] Griwijoyo, Dikdik. Ilmu faal olahraga :fisiologi olahraga. Bandung: Remaja Rosda Karya; 2012.

[13] Ganong WF. Buku ajar fisiologi kedokteran. Edisi 22. Jakata: EGC; 2008.

[14] Sunaryo T, Sudiro. Pengaruh senam diabetik terhadap penurunan risiko ulkus kaki diabetik pada pasien DM tipe 2 di perkumpulan diabetik.Jurnal Terpadi IImu Kesehatan [Internet]. 2014 [diambil tanggal 16 Februari 2016];3(1):99-105 dari: http://www.poltekkessolo.ac.id/attachments/226 PENGARUH $\% 20$ SENAM $\% 20$ DIABETIK\%20

[15] Sukatemin. Kejadian ulkus kaki diabetik : kajian hubungan $\mathrm{HbA} 1 \mathrm{C}$, hiperglikemia, dislipidemia dan status vaskuler berdasarkan pemeriksan ankle brachial index/ABI. Tesis. Yogyakarta: Program Studi Magister Keperawatan Universitas Muhammadiyah Yogyakarta; 2013.

[16] Ahmad W, Khan Al, Ghaffar S, Al-Swailmi FA, Khan I. Risk factors for diabetic foot ulcer. J Ayub Med Coll Abbottabad [Internet]. 2013 [diambil tanggal $15 \mathrm{Mei}$ 2016];25(1):8-16.dari: http://www.ayubmed.edu.pk/JAMC/25-
1/Wasim.pdf

[17] Suhartini P. Teori penuaan, perubahan pada sistem tubuh dan implikasinya pada manusia. Skripsi. Semarang: Program Studi IImu Keperawatan Universitas Diponegoro;2010.

[18] Khaier N. Faktor-faktor yang mempengaruhi kejadian ulkus diabetikum pada pasien diabetes melitus tipe 2. Jurnal IImu Keperawatan Indonesia[Internet] 2015 [diambil tanggal 15 Mei 2015];5(2):1-19. dari;

http://journal.stikim.ac.id/journal/pdf/JURNA L\%20KEPERAWATAN/JURNAL\%20PDF

[19] Sugiarto I. Faktor risiko yang berhubungan dengan terjadinya ulkus diabetik pada pasien diabetes melitus tipe 2 di Rsud. Dr. Margono Soekarjo Purwokerto.Skripsi. Purwokerto: Universitas Jendral Soedirman.

[20]Lestari D, Citrakesumasari, Alharini S. Upaya penanganan dan perilaku pasien penderita diabetes melitus tipe 2 di Puskesmas Maradekaya Kota Makassar. [Internet] 2013 [diambil tanggal 26 Mei 2016] dari

https://www.mysciencework.com/publication /show/dfeb14bf6546aba958df6c84be41748 2

[21] Price SA, Wilson LMC. Patofisiologi: konsep klinis proses-proses penyakit, edisi 6, vol 2, Alih bahasa, Brahm U.Pendit. Jakarta: EGC;2006.

[22] Semendawai RK. Pengaruh latihan fisik senam kaki terhadap efektivitas fungsi sensori di daerah telapak kaki pada penderita diabetes melitus di Puskesmas Kedung Mundu Kota Semarang Jawa Tengah. Skripsi. Semarang: Fakultas IImu Keperawatan dan Kesehatan Universitas Muhammadiyah Semarang; 2013.

[23] Tandra H. Segala sesuatu yang harus anda ketahui mengenai diabetes dengan cepat dan mudah. Jakarta: PT. Gramedia Pustaka Utama; 2007.

[24] Isral GN, Afriwardi, Sulastri D. Hubungan aktivitas fisik dengan kadar nitric oxide (NO) plasma pada masyarakat di Kota Padang. Jurnal Kesehatan Andalas[Internet]; 3(2):173-1772014[diambil tanggal 11 Juni 2016] dari: http://lib.ui.ac.id/file? file=digital $/ 20300843-T 30470 \% 20$ \%20Pengaruh\%20senam.pdf

[25] Jenkins L. Maximizing range of motion in older adults. The Journal on Active Aging[Internet] 2005 [diambil tanggal [10 Juni 2016] dari: 
http://www.humankinetics.com/acucustom/si tename/Documents/Documentltem/rangeof motion.pdf

[26] Fernando DJS, Masson EA, Veves A, Boulton AJM. Relationship of limited joint mobility to abnormal foot pressure and diabetic foot ulceration. Diabetes care[Internet]. 1991 [diambil tanggal 07 Juni 2016];14(1):

8-11.dari: http://care.diabetesjournals.org/content/diac are/14/1/8.full.pdf

[27] Andreassen CS, Jakobsen J, Andersen $\mathrm{H}$. Muscel weakness : a progressive late complication in diabetic distal symmetric polyneuropathy. Diabetes[Internet] 2006 [diambil tanggal 13 Juni 2016];55(3):806812. dari:

http://www.ncbi.nlm.nih.gov/pubmed/165052 47

[28] Widyawati IY. Pengaruh latihan rentang gerak sendi bawah secara aktif (Active Lower Range of Motion Exercise) terhadap tanda dan gejala neuropati diabetikum pada penderita DM Tipe II di Persedia Unit RSU Dr. Soetomo Surabaya. Tesis. Depok: Program Paska Sarjana Fakultas IImu Keperawatan Universitas Indonesia; 2010

[29] Sumpio. Foot ulcers.[Internet] New Haven; 2000 [diambil tanggal 07 Juni 2016]dari : http://www.nejm.org/doi/full/10.1056/NEJM2 00009143431107

[30]Misnadiarly. Diabetes mellitus : ulcer, gangren, infeksi [Intenet] Jakarta: Pustaka Populer Obor; 2006 [diambil tanggal 11 Juni 2016]

dari: https://books.google.co.id/books? id=UYMwK10k92kC\&printsec=frontcover\#v =onepage\&q\&f=true 